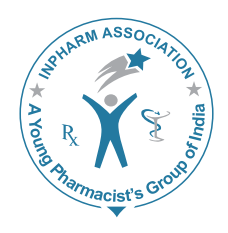

\title{
JVP
}

\section{Preparation and Characterization of Pioglitazone Cyclodextrin Inclusion Complexes}

\author{
Pandit V, Gorantla R, Devi K, Pai RS, Sarasija S \\ Department of Pharmaceutics, Al-Ameen College of Pharmacy, Bangalore, ${ }^{1}$ Department of Pharmaceutical \\ Technology (Formulations), National Institute of Pharmaceutical Education and Research (NIPER), \\ Punjab, India
}

Address for correspondence: Dr. Sarasija Suresh; E-mail: sarasija_s@hotmail.com

\begin{abstract}
Pioglitazone, a class II Biopharmaceutical Classification System drug having poor water solubility and slow dissolution rate may have a negative impact on its subtherapeutic plasma drug levels leading to therapeutic failure. In order to improve its water solubility and thus dissolution, cyclodextrin complexation technique was followed. The phase solubility studies were carried using three different types of cyclodextrins viz., $\beta$, methyl- $\beta$ and $\gamma$-cyclodextrins. The Gibbs free energy was calculated in order to determine ease of the complexation. Binary systems of pioglitazone with cyclodextrins were prepared by kneading method and spray drying method. The phase solubility profiles with all the three cyclodextrins were classified as $\mathrm{A}_{L}$-type, indicating the formation of 1:1 stoichiometric inclusion complexes. The complexation capability of cyclodextrins with pioglitazone increased in the order of methyl- $\beta>\beta>\gamma$-cyclodextrin. The Gibbs free energy was found to be in the order $\gamma>$ methyl $\beta>\beta$ cyclodextrin. Characterization of inclusion complexes was done by solubility studies, in vitro dissolution studies, Fourier transformation-infrared spectroscopy, scanning electron microscopy, differential scanning calorimetry and X-ray powder diffractometry studies. Inclusion complexes exhibited higher rates of dissolution than the corresponding physical mixtures and pure drug. Greater solubility was observed with spray-dried methyl- $\beta$ cyclodextrin complexes $(2.29 \pm 0.001 \mathrm{mg} / \mathrm{ml})$ in comparison to the kneaded methyl $\beta$ cyclodextrin complexes $(1.584 \pm 0.053 \mathrm{mg} / \mathrm{ml})$ and pure drug $(0.0714 \pm 0.0018 \mathrm{mg} / \mathrm{ml})$.
\end{abstract}

Key words: Inclusion complexes, methyl- $\beta$ cyclodextrin, phase solubility, pioglitazone, solubility, spray drying

\section{INTRODUCTION}

Diabetes mellitus is one among the chronic diseases, increasing in numbers and significance due to changing lifestyle in nearly all countries. The world prevalence of

\begin{tabular}{|l|l|}
\hline \multicolumn{2}{|c|}{ Access this article online } \\
\hline Quick Response Code: & \\
\hline & Website: \\
& www.jyoungpharm.in \\
& DOI: \\
\hline
\end{tabular}

diabetes in 2010 is $6.4 \%$, affecting 285 million adults and may be around $7.7 \%$ by 2030 affecting 439 million adults. There may be a $69 \%$ increase in number of diabetics in developing countries and about $20 \%$ increase in developed countries by $2030 \cdot{ }^{[1]}$

Diabetes is a metabolic disease occurring when the pancreas does not produce enough insulin or when the produced insulin cannot be effectively used by the body leading to serious damage to the body's systems. ${ }^{[2]}$

Thiazolidinediones (TZDs), a class of oral hypoglycemic agent reverses few metabolic processes which are 
responsible for development of insulin resistance leading to type 2 diabetes mellitus. TZDs act through nuclear hormone, peroxisome proliferator activated receptor- $\gamma$ (PPAR $\gamma$ ) which increases insulin sensitivity by enhancing the expression of proteins responsible for modulating glucose and lipid metabolism leading to improved insulin sensitivity in the liver, muscle and adipose tissue. Members of the class TZDs include troglitazone, pioglitazone, darglitazone and rosiglitazone. ${ }^{[3,4]}$

Pioglitazone, a member of the thiazolidinedione group of drugs used for the treatment of type 2 diabetes mellitus. The solubility of its hydrochloride salt is low which may have a negative impact on its dissolution rate, leading to subtherapeutic plasma drug levels affecting therapeutic action. Methods for increasing the aqueous solubility of poor soluble drugs include: Complexation, addition of surface active agents, preparation of soluble prodrug, cosolvency, salt formation, hydrotropism, crystal engineering and addition of ionic liquids. Among these approaches, preparation of cyclodextrin (CD) inclusion complexes of the drug has proven effective in enhancing the solubility of poorly water-soluble drugs. ${ }^{[5-7]}$

CDs are glucopyranose units linked by $\alpha-(1,4)$ bonds consisting of six to more than 100 glucose units. Intramolecular transglycosylation reaction of starch by CD glucanotransferase (CGTase) enzyme yields a mixture of CDs like $\alpha$-, $\beta$ - and $\gamma$-CDs consisting of six, seven or eight glucose units, respectively.

CDs form inclusion complexes with a wide range of hydrophobic molecules. In solution, the hydrophobic CD cavity is occupied by water molecules which are bounded by "weak forces" that can be substituted by hydrophobic molecules such as drugs to form complexes. Depending on the size of the internal cavity, one or two hydrophobic molecules can be entrapped by one, two or even three CDs. ${ }^{[8]}$

In the present research work, inclusion complexes of pioglitazone with CDs were prepared by kneading method for comparative evaluation of $\beta$-cyclodextrin, its water soluble derivative methyl- $\beta$ cyclodextrin and $\gamma$-cyclodextrin. As per the solubility studies of kneaded complexes, $\mathrm{M}-\beta C D$ was selected for preparation of complexes by spray drying method to further enhance the solubility of pioglitazone. Further formation of complexes was confirmed by solubility studies, in vitro dissolution studies, Fourier transformation-infrared spectroscopy (FTIR), scanning electron microscopy (SEM), differential scanning calorimetry (DSC) and X-ray powder diffraction (XRPD) studies.

\section{MATERIALS AND METHODS}

Pioglitazone $\mathrm{HCl}$ was a gift sample from Dr. Reddy's, $\gamma-\mathrm{CD}$ and $\mathrm{M}-\beta \mathrm{CD}$ were kindly provided by Roquette, France, $\beta$-CD was kindly provided by Signet Chemicals, Mumbai. All other chemicals and reagents were of analytical grade.

Phase solubility studies

The stability constants for inclusion complex formations between pioglitazone and $\mathrm{CDs}$ were determined using the phase solubility method (Higuchi and Connors). ${ }^{[9]}$ Samples were prepared by adding $20 \mathrm{ml}$ of distilled water as a media to $30 \mathrm{ml}$ screw-capped bottles containing successively increasing concentration of cyclodextrin as follows $0.5,1,1.5,2.5,5$ and $10 \mathrm{mM}$. Excess amount of pioglitazone was added to each bottle to maintain saturated conditions, in aqueous solutions of $\beta-C D, M \beta-C D$ and $\gamma-C D$ solutions. Each bottle was capped and shaken for $24 \mathrm{~h}$ at $25 \pm 1^{\circ}$. Aliquots were filtered with Whatman filter and complexed pioglitazone was analyzed by UV spectrophotometer $(270 \mathrm{~nm})$.

The apparent stability constants $\left(K_{S}\right)$ were calculated from the straight line portion of the phase solubility using the following Eqn., $\mathrm{K}_{\mathrm{s}}=$ Slope $/ \mathrm{S}_{0}$ (1-Slope), where, $\mathrm{S}_{0}$ is the solubility of drug at $25^{\circ}$ in the absence of CDs and slope means the corresponding slope of the phase-solubility diagrams.

The Gibbs free energies of transfer of drug from aqueous solution to the cavity of cyclodextrin have been calculated from following Eqn., $\Delta \mathrm{G}^{0}=-2.303 \mathrm{RT} \log \left[\mathrm{S}_{0} / \mathrm{S}_{\mathrm{S}}\right]$, where, $\mathrm{S}_{\mathrm{S}}$ and $\mathrm{S}_{0}$ are the solubility of drug in the presence and absence of cyclodextrin, respectively. ${ }^{[10]}$

\section{Preparation of solid binary systems}

The following binary systems of pioglitazone and CDs were prepared at 1:1 molar ratio.

Preparation of physical mixture of pioglitazone and cyclodextrin

The physical mixture (PM) of pioglitazone and CDs viz., $\beta$, methyl $\beta$ and $\gamma$-CD in 1:1 molar ratio was prepared by mixing individual components that had previously been sieved through mesh number $60 .{ }^{[1]}$

Preparation of inclusion complexes by kneading method

Drug and cyclodextrin are weighed in terms of equal molar ratios (1:1). This molar ratio was selected after phase 
solubility studies. $\beta$-CD, $\mathrm{M} \beta-\mathrm{CD}$ or $\gamma-\mathrm{CD}$ was wetted in a ceramic mortar with $50 \%$ ethanol solution until a paste was obtained. Required amount of pioglitazone was added slowly and kneaded for about $45 \mathrm{~min}$. The product was dried at $40^{\circ}$ for $24 \mathrm{~h}$. The dry mass so obtained was powdered and passed through sieve no. 60. Prepared complexes were stored in a desiccator for further studies. ${ }^{[12]}$

Preparation of inclusion complexes by spray drying method

Drug and CD are weighed in terms of equal molar ratios (1:1). This molar ratio was selected after phase solubility studies. Drug was dissolved in $25 \mathrm{ml}$ ethanol-acetone (1:1) mixture with constant stirring and added to a solution of cyclodextrin (M $\beta$-CD) dissolved in $25 \mathrm{ml}$ of same solvent mixture. This mixture of solutions was sonicated for $15 \mathrm{~min}$ and this feed was fed to (Lab Ultima-222, Mumbai) mini spray drier and sprayed into the chamber from a nozzle with a diameter $0.7 \mathrm{~mm}(700 \mu \mathrm{m})$ under the following conditions: Inlet air temperature of $65^{\circ}$, outlet air temperature of $55^{\circ}$, cool temperature of $50^{\circ}$, inlet high of $75^{\circ}$, outlet high of $60^{\circ}$, feed rate of $3 \mathrm{ml} / \mathrm{min}$, atomization air pressure of $2.5 \mathrm{~kg} / \mathrm{cm}^{2}$, aspirator speed $30 \%$ and vacuum in the system of $100 \mathrm{wc} / \mathrm{mm}$. The product thus obtained was collected, packed in aluminum foil and stored in desiccator for further studies.

\section{Characterization of pioglitazone CD inclusion complexes}

\section{Solubility studies}

Excess of prepared inclusion complexes were dispersed in the $20 \mathrm{ml}$ of distilled water in screw-capped bottles to get a supersaturated solution. These bottles were shaken continuously for $4 \mathrm{~h}$ at ambient temperature until equilibrium was attained. Aliquots were filtered with Whatman filter and total pioglitazone was analyzed by spectrophotometer $(270 \mathrm{~nm})$. Solubility studies were also performed for pure drug. ${ }^{[10]}$

\section{In vitro dissolution studies}

In vitro dissolution of pure drug and inclusion complexes were studied in USP XXIII dissolution apparatus (Electrolab) employing a paddle stirrer at $75 \mathrm{rpm}$ and using $500 \mathrm{ml}$ of distilled water at $37 \pm 0.1^{\circ}$ as dissolution medium. Complexes equivalent to $15 \mathrm{mg}$ of pioglitazone was used in each test. Aliquots of dissolution medium $(5 \mathrm{ml})$ were withdrawn at known intervals of time and filtered through Whatman filter paper and $1 \mathrm{ml}$ of the filtrate was made up to $10 \mathrm{ml}$ with $0.2 \mathrm{~N} \mathrm{HCl}$ in $10 \mathrm{ml}$ volumetric flasks. Suitable dilutions were further made when required. The absorbance of the samples was read at $270 \mathrm{~nm}$ against blank. The aliquot withdrawn at each time interval was replaced with the same volume of fresh dissolution medium. All the experiments were run in triplicate. ${ }^{[13]}$

\section{Fourier transformation-infrared spectroscopy}

Infrared spectra were obtained using Shimadzu Fourier transformation-infrared (FTIR)-8700 spectrophotometer using $\mathrm{KBr}$ disks. The samples of pioglitazone, $\mathrm{M} \beta-\mathrm{CD}$, physical mixtures of pioglitazone and $\mathrm{M} \beta-\mathrm{CD}$ and inclusion complexes were previously ground and mixed thoroughly with $\mathrm{KBr}$. The $\mathrm{KBr}$ disks were prepared by compressing the powder. The scanning range was kept from 4000 to $450 \mathrm{~cm}^{-1}$.

\section{Scanning electron microscopy studies}

The surface morphology of pioglitazone, physical mixtures and inclusion complexes was examined by using Scanning electron microscopy (SEM). The small amount of powder was manually dispersed onto a carbon tab adhered to an aluminum stubs. Then these stubs were coated with a thin layer of gold by employing POLARON-E 3000 sputter coater. The samples were examined using Joel JSM 840A SEM and photographed under various magnifications with direct data capture of the images onto a computer.

\section{Differential scanning calorimetry studies}

Differential scanning calorimetry of pioglitazone, $\mathrm{M} \beta-\mathrm{CD}$, physical mixtures and inclusion complexes were conducted using Differential scanning calorimetry (DSC) Q2000 V24.2 Build 107 instrument. The mass of empty pan and reference pan were taken into account for calculation of heat flow. The sample mass varied from 3-10 $\pm 0.5 \mathrm{mg}$ and it was placed in sealed aluminum pans. The coolant used was liquid nitrogen. The samples were scanned at $10^{\circ} / \mathrm{min}$ from $20^{\circ}$ to $300^{\circ}$.

\section{$X$-ray powder diffractometry studies}

X-ray powder diffractometry (XPRD) patterns for pioglitazone, $\mathrm{M} \beta-\mathrm{CD}$, physical mixtures and inclusion complexes were traced employing X-ray diffractometer (Bruker Axs D8 Advance, Germany) with scanning rate $4^{\circ} / \mathrm{min}$ and voltage/current used was $40 \mathrm{kV} / 50 \mathrm{~mA}$ and the target/filter was copper.

\section{Stability studies}

The prepared selected formulation was stored at $40^{\circ} \mathrm{C} \pm$ $2{ }^{\circ} \mathrm{C} / 75 \% \mathrm{RH} \pm 5 \% \mathrm{RH}$ in Newtronic Temperature/ Humidity Control Chamber QLH- 2004 for a period of 
6 months. The samples were withdrawn every month and were evaluated for drug content and in vitro dissolution studies.

\section{RESULTS AND DISCUSSION}

\section{Phase solubility studies}

The phase solubility diagram for the complex formation between pioglitazone and $\beta-\mathrm{CD} / \mathrm{M} \beta-\mathrm{CD} / \gamma-\mathrm{CD}$ are presented in the Figure 1. The plots show that aqueous solubility of pioglitazone increases linearly as a function of cyclodextrin concentration up to $2.5 \mathrm{mM}$. It is clearly observed that the solubility diagram of pioglitazone in the presence of $\beta-C D / M \beta-C D$ and $\gamma-C D$ can be classified as $A_{L}$ type according to Higuchi and Connors. As slope is less than 1 and the plot is $A_{L}$ type, 1:1 ratio of drug and the respective $\mathrm{CD}$ is selected for complexation. The apparent stability constants $\left(\mathrm{K}_{s}\right)$ were calculated from the straight line portion of the phase solubility diagram [Table 1]. The cavity size of $\mathrm{M} \beta$-CD seems to be optimal for entrapment of pioglitazone molecules as it provides the greatest solubilization effect. Stability constants obtained for pioglitazone are in the rank order of methyl- $\beta>\beta>\gamma$-CD.

The change in Gibb's free energy $\left(\Delta G^{0}\right)$ is the net energy available to do useful work and is a measure of the "free energy" [Table 2]. $\Delta G^{0}$ gives criteria for spontaneity at constant pressure and temperature. ${ }^{[14]}$ If $\Delta G^{0}$ is negative, the process is spontaneous. As $\Delta \mathrm{G}^{0}$ becomes more negative, the reaction becomes more favorable. In the present case, the reaction consists of the solubility of the drug in cyclodextrin solution. $\Delta \mathrm{G}^{0}$ is related to the equilibrium constant of a reaction $\mathrm{K}$, by the relation $\Delta \mathrm{G}^{0}=-2.3 .3 \mathrm{RT} \log \mathrm{K}$ where $\mathrm{K}$ is calculated from $\left(\mathrm{S}_{0} / \mathrm{S}_{\mathrm{s}}\right)$. It was observed that $\Delta \mathrm{G}^{0}$ values obtained were negative which increased with increasing $\mathrm{CD}$ concentration in all the different types of CDs evaluated in this study. This indicates that CD solutions offer a more favorable environment than water for pioglitazone.

\section{Preparation of inclusion complexes}

\section{Preparation of inclusion complexes by kneading method}

Cyclodextrin complexes of pioglitazone were prepared using 1:1 $\mathrm{M}$ ratio of drug and the corresponding CD's $(\beta-C D$, $\mathrm{M} \beta-\mathrm{CD}$ and $\gamma-\mathrm{CD})$ as indicated by phase solubility studies. The products formed were free flowing in nature and white in color. The prepared complexes subjected to solubility analysis showed a constant reading after $4 \mathrm{~h}$ studies.

The solubility studies indicated that among the prepared complexes, $\mathrm{M} \beta-\mathrm{CD}$ complexes had maximum solubility
Table 1: Stability constants $\left(K_{s}\right)$ and slope for pioglitazone-CD complexes

\begin{tabular}{lcc}
\hline Type of cyclodextrin & Slope & Stability constant $\left(\mathbf{M}^{-1}\right)$ \\
\hline Methyl $\beta$-cyclodextrin & 0.331 & 2747.19 \\
$\beta$-cyclodextrin & 0.2073 & 1452.03 \\
$\gamma$-cyclodextrin & 0.0337 & 359.06 \\
\hline
\end{tabular}

\section{Table 2: Gibbs free energy of pioglitazone-CD} complexes in water

\begin{tabular}{lccc}
\hline $\begin{array}{l}\text { Conc. of } \\
\text { cyclodextrin }(\mathbf{m M})\end{array}$ & \multicolumn{3}{c}{ Gibbs free energy $-\Delta_{\text {trans }} \mathbf{G}^{\mathbf{0}} / \mathbf{c a l} / \mathbf{m o l}^{-1}$} \\
\cline { 2 - 4 } & $\mathbf{M} \beta-\mathbf{C D}$ & $\beta-\mathbf{C D}$ & $\gamma$-CD \\
\hline 0.5 & 23.029 & 138.408 & 50.591 \\
1 & 186.669 & 225.554 & 77.101 \\
1.5 & 218.183 & 309.973 & 87.105 \\
2.5 & 347.773 & 328.5194 & 93.967 \\
5 & 391.918 & 354.926 & 135.441 \\
10 & 308.662 & 497.496 & 187.934 \\
\hline mM, millimolar; $\mathrm{M} \beta$-CD, methyl $\beta$-cyclodextrin; $\beta$-CD is $\beta$-cyclodextrin; $\gamma$-CD is \\
$\gamma$-cyclodextrin
\end{tabular}

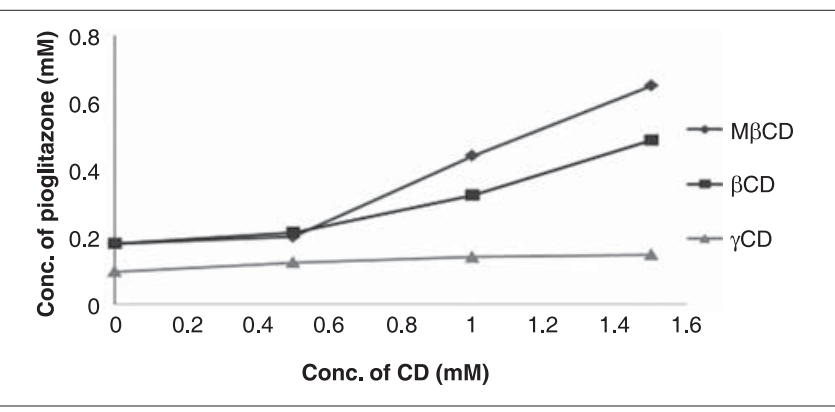

Figure 1: Phase solubility diagram of pioglitazone $\mathrm{HCl}$

$(1.584 \pm 0.053 \mathrm{mg} / \mathrm{ml})$ and therefore selected for further evaluation.

Preparation of inclusion complexes by spray drying method Spray drying method represents one of the most commonly employed methods to produce the inclusion complexes starting from a solution. The mixture is passed to a fast elimination system to produce complexes having high efficiency. ${ }^{[15]}$

As per the solubility studies of kneaded complexes, $\mathrm{M} \beta-\mathrm{CD}$ was selected for preparation of drug complexes by spray drying method.

As pioglitazone is insoluble in water the same cannot be used as solvent. Precipitation must be controlled in order to avoid the particles blocking the atomizer or spray nozzle, hence clear solution is desirable. ${ }^{[16]}$

Ethanol-acetone mixture in different ratios was used as solvent system for preparation of complexes based on solubility of drug and M $\beta$-CD. 1:1 ratio was selected as it gave a clear solution whereas other ratios formed a turbid solution. 
The process parameters for spray drying technique were optimized in preliminary studies. The various process parameters considered were inlet air temperature, outlet air temperature, feed rate, atomization air pressure and aspirator speed.

The inlet air temperature and outlet air temperature was optimized to $65^{\circ}$ and $55^{\circ}$, respectively, based on boiling point of the solvents used and stability of the drug to get dry and stable product.

The different feed rates i.e., 3, 5 and $7 \mathrm{ml} / \mathrm{min}$ were selected. It was found that higher the feed rate, lower was the yield. When the feed rate was kept at $2 \mathrm{ml} / \mathrm{min}$ the yield was decreased and the time taken for the process was long. Therefore, $3 \mathrm{ml} / \mathrm{min}$ was selected as optimum feed rate to get maximum yield of the complexes.

Atomization air pressure and aspirator speed were optimized at $2.5 \mathrm{~kg} / \mathrm{cm}^{2}$ and 30 , respectively, so as to achieve good yield and decrease the time taken for the process.

The product formed was white in color and free flowing in nature. However, the yield was less compared to kneading method due to adherence of the product to the drying chamber and accumulation in scrubber. The product obtained by this method had uniform particles which in turn improves the solubility and thus dissolution rate of drug in complex form.

\section{Solubility studies}

Pioglitazone complexes were subjected to solubility studies in water and the results were shown in Table 3. It was observed kneaded $\mathrm{M} \beta-\mathrm{CD}$ complexes exhibited the solubility of $1.584 \pm 0.053 \mathrm{mg} / \mathrm{ml}$ whereas kneaded $\gamma$-CD and kneaded $\beta$-CD complexes exhibited the solubility of $0.1448 \pm 011 \mathrm{mg} / \mathrm{ml}$ and $0.425 \pm 0.041 \mathrm{mg} / \mathrm{ml}$, respectively. Based on this solubility data $\mathrm{M} \beta-\mathrm{CD}$ was selected for preparing drug complexes by spray drying technique in order to further enhance the solubility of pioglitazone.

$\mathrm{M} \beta-\mathrm{CD}$ cyclodextrin complex prepared by spray drying method showed a maximum increase in the solubility of $2.29 \pm 0.001 \mathrm{mg} / \mathrm{ml}$. The complexes prepared by spray drying method showed a 32-fold increase in solubility than the pure drug $(0.0714 \pm 0.0018 \mathrm{mg} / \mathrm{ml})$ as shown in Figure 2.

\section{In vitro dissolution studies}

The prepared kneaded complexes of $\beta$-CD, $M \beta$-CD and $\gamma$-CD along with $\mathrm{M} \beta-\mathrm{CD}$ complexes prepared by spray drying technique were subjected for dissolution studies. It was observed that spray-dried complexes has shown the drug release of $84.66 \%$ in $60 \mathrm{~min}$ where as $\gamma$-CD, $\beta$-CD and $\mathrm{M} \beta$-CD-kneaded complexes showed release of $34.71 \%, 41.64 \%$ and $51.13 \%$ in $60 \mathrm{~min}$. The enhanced dissolution rate of spray-dried products might be attributed to decreased particle size, increased surface area and formation of uniform-sized complexes. The dissolution profile obtained for inclusion complexes is shown in Figure 3.

Characterization studies such as FTIR, SEM, DSC and XRPD were further carried for drug-M $\beta C D$ kneaded and spray-dried complexes, in order to determine formation of inclusion complex.

\section{Fourier transforms infrared spectroscopy studies}

The IR spectra of pure drug, physical mixtures of pioglitazone-M $\beta-\mathrm{CD}$ and complexes are shown in Figure 4. The IR spectrum of pioglitazone revealed the presence of peak at $3085.89 \mathrm{~cm}^{-1}$ due to N-H stretching while peaks at 2927.74 and $2740.66 \mathrm{~cm}^{-1}$ is due to aliphatic C-H stretching. Strong absorption peaks observed at 1743.53 and $1689.53 \mathrm{~cm}^{-1}$ were assigned to drug carbonyl stretching vibration $(\mathrm{C}=\mathrm{O})$. A peak at $1612 \mathrm{~cm}^{-1}$ indicates the

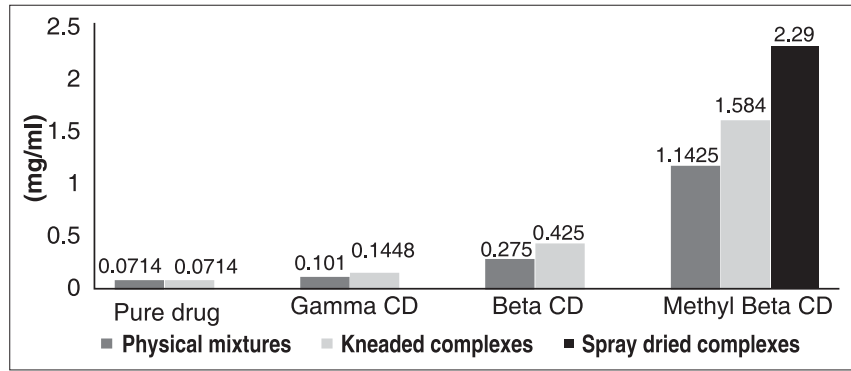

Figure 2: Solubility profile of complexes in water

Table 3: Solubility studies of the prepared complexes

\begin{tabular}{|c|c|c|c|c|}
\hline \multirow[t]{2}{*}{ Complexation technique } & \multirow[t]{2}{*}{$*$ Solubility of pure drug $(\mathrm{mg} / \mathrm{ml}) \pm \mathrm{SD}$} & \multicolumn{3}{|c|}{ *Solubility of complexes $(\mathrm{mg} / \mathrm{ml}) \pm \mathrm{SD}$} \\
\hline & & $\gamma-C D$ & $\beta-C D$ & Mß-CD \\
\hline Physical mixtures & $0.0714 \pm 0.0013$ & $0.101 \pm 0.0013$ & $0.275 \pm 0.0043$ & $1.1425 \pm 0.003$ \\
\hline Kneading & $0.0714 \pm 0.0023$ & $0.144 \pm 0.0022$ & $0.425 \pm 0.0031$ & $1.584 \pm 0.0042$ \\
\hline Spray drying & $0.0714 \pm 0.0018$ & - & - & $2.29 \pm 0.001$ \\
\hline
\end{tabular}

SD-standard deviation; $\gamma$-CD is $\gamma$-cyclodextrin; $\beta$-CD is $\beta$-cyclodextrin; $\mathrm{M} \beta$-CD is methyl $\beta$-cyclodextrin. *Average of three determinations 


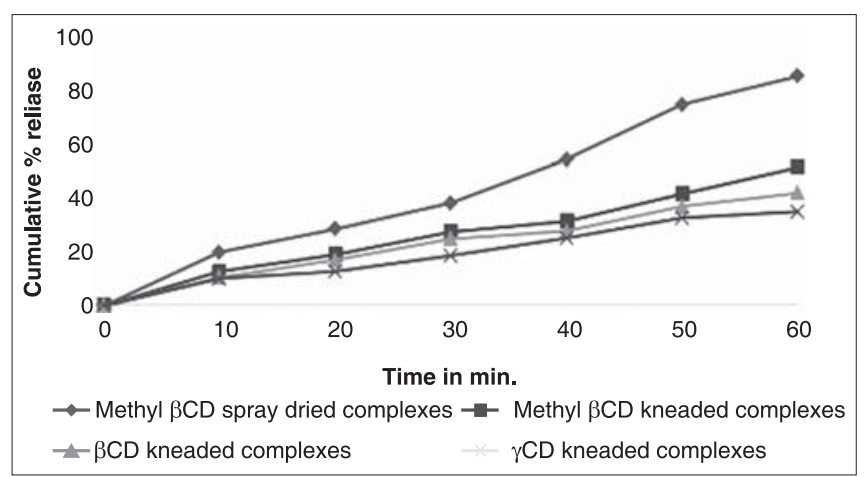

Figure 3: In vitro dissolution studies of CD complexes

aromatic ring and a peak at $1238 \mathrm{~cm}^{-1}$ is due to $\mathrm{C}-\mathrm{O} \mathrm{Ar}$ group. $\mathrm{M} \beta$-CD showed prominent peak at $3402.2 \mathrm{~cm}^{-1}$ due to $\mathrm{O}-\mathrm{H}$ stretching. Physical mixture of drug and $\mathrm{M} \beta-\mathrm{CD}$ shows summation of the spectra of the drug and $M \beta-C D$, equivalent to the addition of the spectrum of cyclodextrin and drug. So presence of all these characteristic peaks of pioglitazone in physical mixture reveals that the drug remains intact and there is no interaction between drug and excipients. Whereas all peaks of pioglitazone were found to be smoothened in complexes indicating strong physical interaction of pioglitazone with $\mathrm{M} \beta-\mathrm{CD}$. The peak of $\mathrm{OH}$ group of $\mathrm{M} \beta-\mathrm{CD}$ at $3402.2 \mathrm{~cm}^{-1}$ was shifted toward lower frequency due to intermolecular hydrogen bonding with pioglitazone in both kneaded and spray-dried complexes.

The peak at $1635.52 \mathrm{~cm}^{-1}$ in IR spectra of $\mathrm{M} \beta$-CD due to water of crystallization, disappeared in both the inclusion complexes. The binary systems of pioglitazone-M $\beta-\mathrm{CD}$ did not show any new peaks, indicating no chemical bond formation in the complexes and formation of inclusion complex in solid state. Changes in the characteristic bands of pure drug confirm the existence of the complex as a new compound with different spectroscopic bands.

\section{Scanning electron microscopy studies}

SEM study indicated that pure drug particles were irregular in shape, whereas $\mathrm{M} \beta-\mathrm{CD}$ showed spherical particles. The physical mixture of the drug and $\mathrm{M} \beta-\mathrm{CD}$ shows that drug particle remains dispersed and physically adsorbed on the surface of the $\mathrm{M} \beta-\mathrm{CD}$ particles.

Following inclusion complexation of drug with $\mathrm{M} \beta-\mathrm{CD}$ by kneading and spray drying methods, $\mathrm{M} \beta-\mathrm{CD}$ showed loss of sphericity, smooth surface and reduced size of the particles. A drastic change in the morphology and shape of the drug particles was observed in the inclusion complex, it was no longer possible to differentiate the two components, drug-M $\beta-C D$ complexes and $M \beta-C D$. Hence changes in the particle shape and size, suggested an apparent

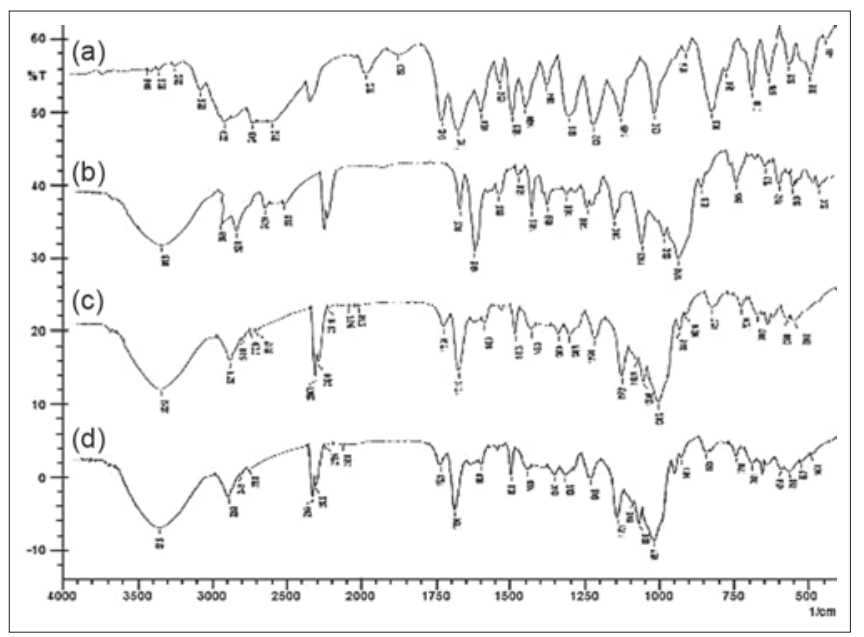

Figure 4: IR spectra of (a) pure pioglitazone (b) physical mixture of pioglitazone and pure $\mathrm{M} \beta-\mathrm{CD}$ (c) kneaded complexes (d) spray-dried complexes

interaction between drug and M $\beta-\mathrm{CD}$ [Figure 5].

\section{Differential scanning calorimetry studies}

The DSC thermogram of pure drug, $\mathrm{M} \beta-\mathrm{CD}$, physical mixtures and complexes are shown in Figure 6. The DSC thermogram of pure pioglitazone showed an endothermic peak at $201.9^{\circ}$, corresponding to its melting point. Peak at $68.13^{\circ}$ observed for $\mathrm{M} \beta-\mathrm{CD}$ thermogram corresponds to its dehydration process.

The thermogram of pioglitazone and $\mathrm{M} \beta-\mathrm{CD}(1: 1)$ physical mixture showed two peaks. The peak at $63.13^{\circ}$ is due to dehydration process of $\mathrm{M} \beta-\mathrm{CD}$ and peak at $196.9^{\circ}$ is the shift of drug peak to a lower temperature, indicating that a true complex has not formed.

DSC can be used for the recognition of inclusion complexes. When guest molecules are embedded in CD cavities, their melting, boiling or sublimation points generally shift to a different temperature or disappear. The thermal curve of pioglitazone and $\mathrm{M} \beta-\mathrm{CD}$ (1:1) complex prepared by kneading method showed only one peak at $181.1^{\circ}$ and those prepared by spray dried showed a peak at $154.1^{\circ}$ which is due to dehydration process of $\mathrm{M} \beta-\mathrm{CD}$. The disappearance of endothermic peak due to pioglitazone with these systems indicated the formation of true complex of pioglitazone and $\mathrm{M} \beta-\mathrm{CD}$ at 1:1 $\mathrm{M}$ ratio.

\section{$X$-ray powder diffraction studies}

The X-ray diffraction patterns of pure drug, $M \beta-C D$ and complexes are shown in Figure 7. In the X-ray diffractogram of pioglitazone it is possible to observe several sharp peaks in the range from 0 to 30 (degrees $2 \theta$ ) suggesting that the drug is present in a crystalline form. On the other hand, the 

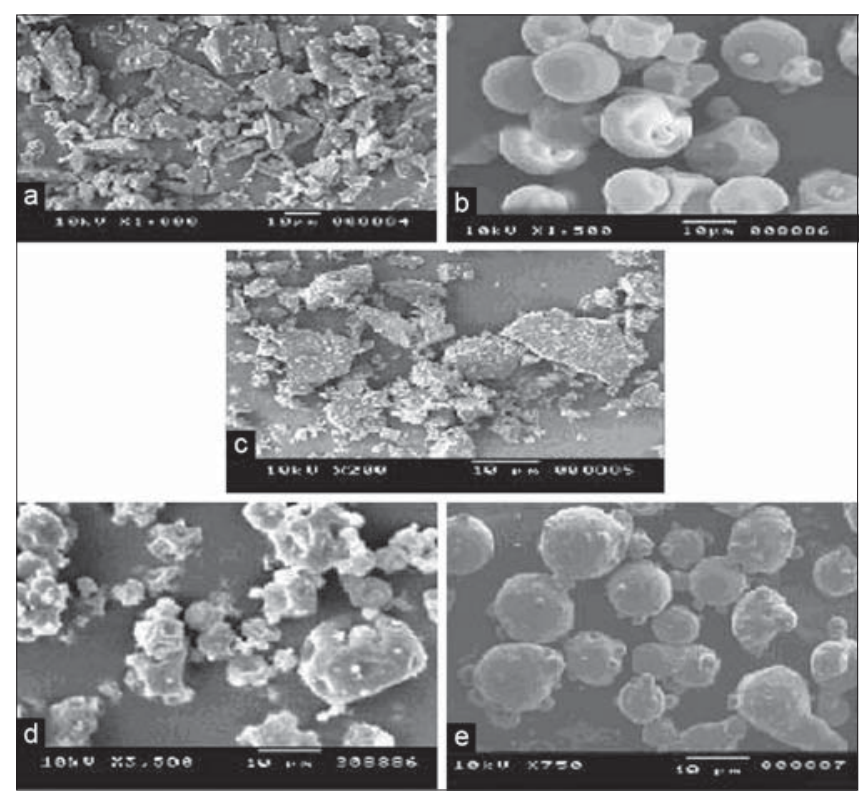

Figure 5: Scanning electron microscopy of (a) pure pioglitazone (b) pure $M \beta-C D$ (c) physical mixtures (d) kneaded complexes (e) spray-dried complexes

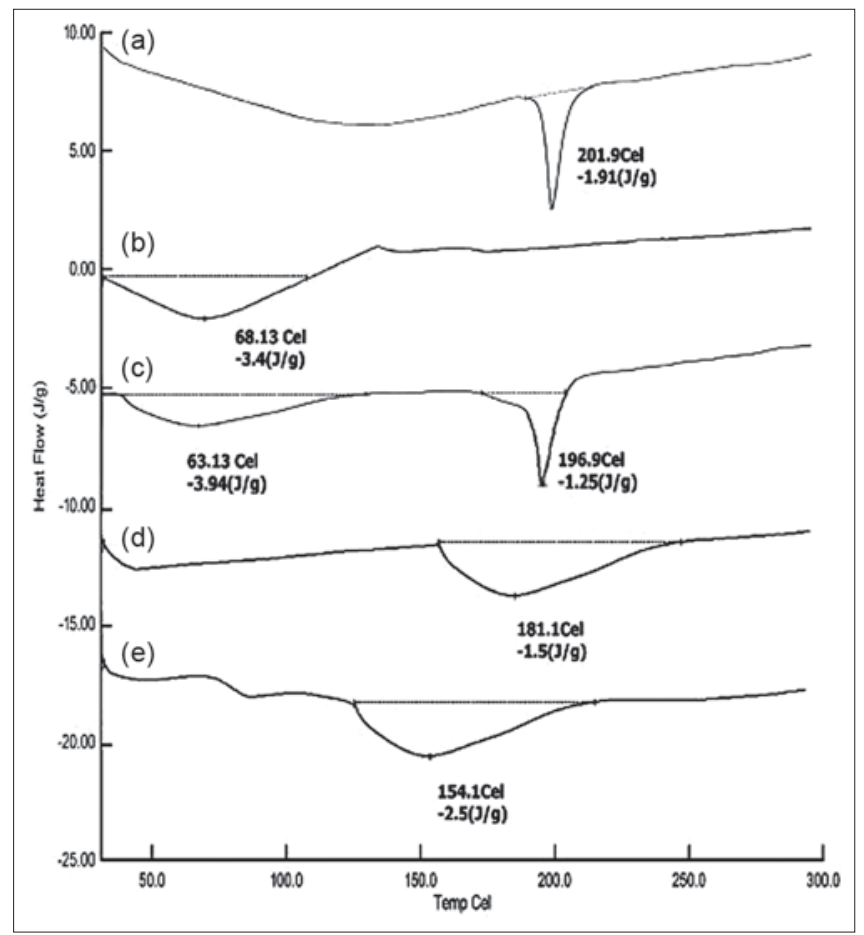

Figure 6: DSC of (a) pure pioglitazone (b) pure M $\beta-C D$ (c) physical mixtures (d) pioglitazone kneaded complexes (e) pioglitazone spray-dried complexes

XRPD pattern of $\mathrm{M} \beta-\mathrm{CD}$ confirms its amorphous form. In the case of the physical mixtures the XRPD spectrum is simply the superposition of those of the single components. A decrease in the peak intensity, crystallinity loss, was observed in the physical mixtures diffractogram, probably due to the amorphous character of the cyclodextrin.
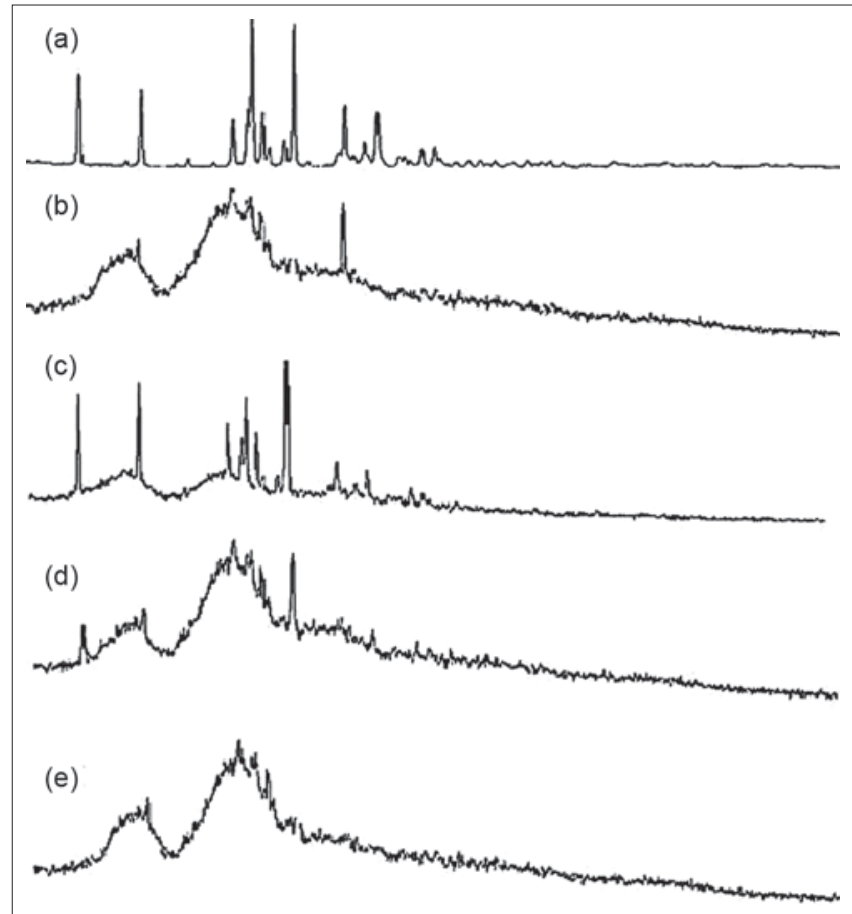

Figure 7: XRPD of (a) pure pioglitazone (b) pure $M \beta-C D$ (c) physical mixtures (d) pioglitazone kneaded complexes (e) pioglitazone spray-dried complexes

XRPD is a useful method for the detection of cyclodextrin complexation in powder or microcrystalline states. The diffraction pattern of the complex is supposed to be clearly distinct from that of drug and $C D$.

Crystallinity is determined by comparing representative peak heights in the diffraction patterns. In both kneaded and spray-dried complexes some characteristic pioglitazone peaks were still detectable but with lower intensity indicating that the crystallinity of the drug was reduced to a great extent and conversion into an amorphous state. No new peaks could be observed, suggesting the absence of interaction between the drug and the carrier.

\section{Stability studies}

The selected formulation was subjected to accelerated stability studies as per ICH guidelines for 6 months. The samples were tested for any changes in physical appearance, drug content and in vitro dissolution profile at monthly intervals. The results showed that there was no significant difference $(P>0.05)$ in the drug content and dissolution behavior of the selected formulation.

\section{CONCLUSIONS}

In the present work an attempt has been made to achieve 
faster onset of hypoglycemic action with pioglitazone by enhancement of solubility through complexation with CDs. Phase solubility studies indicated the formation of complexes in 1:1 $\mathrm{M}$ ratio, forming highly stable inclusion complex with methyl $\beta$-CD followed by $\beta-C D$ and $\gamma$-CD. Pioglitazone-M $\beta$-CD systems allowed a marked improvement of the initial drug water solubility. In particular, an increase of about 22 times was obtained for kneaded product and about 32 times for spray-dried product. FTIR, SEM, DSC and XRPD studies showed that complexes can be prepared by kneading and spray-drying methods demonstrating that spray drying can be efficient method for inclusion complex formation between pioglitazone and $\mathrm{M} \beta-\mathrm{CD}$.

\section{ACKNOWLEDGMENT}

The authors would like to thank Prof. B.G. Shivananda, Principal, Al-Ameen College of Pharmacy for his kind support and encouragement.

\section{REFERENCES}

1. Shaw JE, Sicree RA, Zimmet PZ. Global estimates of the prevalence of diabetes for 2010 and 2030. Diabetes Res Clin Pract 2010;87:4-14.

2. Available from: http://www.who.int/mediacentre/factsheets/fs312/en/ index.html. [cited on 2010 Oct 14].

3. Grossman L. New solutions for type 2 diabetes mellitus the role of pioglitazone. Pharmacoeconomics 2002;20(Suppl 1):1-9.
4. Reginato MJ, Lazar MA. Mechanisms by which Thiazolidinediones enhance insulin action. Trends Endocr Metab 1999;10:9-13.

5. Gillies PS, Dunn CJ. Pioglitazone. Drugs 2000;60:333-43.

6. Jouyban A, Soltanpour S. Solubility of pioglitazone hydrochloride in binary mixtures of polyethylene glycol 400 with ethanol, propylene glycol, N-methyl-2-pyrrolidone, and water at $25^{\circ} \mathrm{C}$. Chem Pharm Bull 2010;55:1132-5.

7. Hiremath SN, Raghavendra RK, Sunil F, Danki LS, Rampure MV, Swamy PV, et al. Dissolution enhancement of gliclazide by preparation of inclusion complexes with $\beta$-cyclodextrin. Asian J Pharm 2008;2:73-6.

8. Knoerr AL, Gref R, Couvreur P. Cyclodextrins for drug delivery. J Drug Targeting 2010;18:1-12.

9. Higuchi T, Connors KA. Phase solubility techniques. Adv Anal Chem Instrum 1965;4:117-212.

10. Asker AF, Whitworth CW. Dissolution of acetyl salicylic acid from acetyl salicylic acid-polyethylene glycol 6000 coprecipitates. Pharmazie 1975;30:530-1.

11. Doiphode D, Gaikwad S, Pore Y, Kuchekar B, Late S. Effect of $\beta$-cyclodextrin complexation on physicochemical properties of zaleplon. J Inclusion Phenom Macrocyclic Chem 2008;62:43-50.

12. Wong JW, Yuen KH. Inclusion complexation of artemisinin with $\alpha$-, $\beta$-, and $\gamma$-Cyclodextrins. Drug Dev Ind Pharm 2003;29:1035-44.

13. Patel RP, Patel MM. Preparation and evaluation of inclusion complex of lipid lowering drug lovastatin with $\beta$-cyclodextrin. Dhaka Univ J Pharm Sci 2007;6:25-36.

14. Patil JS, Kadam DV, Marapur SC, Kamalapur MV. Inclusion complex system: A novel technique to improve the solubility and bioavailability of poorly soluble drugs: A review. Int J Pharm Sci Rev Res 2010;2:29-34.

15. Valle Del EM. Cyclodextrins and their uses: A review. Process Biochem 2004;39:1033-46.

How to cite this article: Pandit V, Gorantla R, Devi K, Pai RS, Sarasija $\mathrm{S}$. Preparation and characterization of pioglitazone cyclodextrin inclusion complexes. J Young Pharmacists 2011;3:267-74.

Source of Support: Nil, Conflict of Interest: None declared.

\section{Author Help: Reference checking facility}

The manuscript system (www.journalonweb.com) allows the authors to check and verify the accuracy and style of references. The tool checks the references with PubMed as per a predefined style. Authors are encouraged to use this facility, before submitting articles to the journal.

- The style as well as bibliographic elements should be $100 \%$ accurate, to help get the references verified from the system. Even a single spelling error or addition of issue number/month of publication will lead to an error when verifying the reference.

- Example of a correct style

Sheahan P, O'leary G, Lee G, Fitzgibbon J. Cystic cervical metastases: Incidence and diagnosis using fine needle aspiration biopsy. Otolaryngol Head Neck Surg 2002;127:294-8.

- Only the references from journals indexed in PubMed will be checked.

- Enter each reference in new line, without a serial number.

- Add up to a maximum of 15 references at a time.

- If the reference is correct for its bibliographic elements and punctuations, it will be shown as CORRECT and a link to the correct article in PubMed will be given.

- If any of the bibliographic elements are missing, incorrect or extra (such as issue number), it will be shown as INCORRECT and link to possible articles in PubMed will be given. 